\title{
The Relationship Between Depression and Sleep Quality in Iranian Pregnant Women
}

\author{
Mojgan Mirghaforvand ${ }^{1}$, Sakine Mohammad-Alizadeh-Charandabi ${ }^{2}$, Somayeh Zarei ${ }^{3}$, \\ Fatemeh Effati- Daryani ${ }^{3}$, Fatemeh Shiri Sarand ${ }^{4^{*}}$
}

\begin{abstract}
Objectives: Many anatomic and physiologic changes occur in women's bodies during pregnancy that make them vulnerable both physically and mentally. Depression is a common disorder that can be accompanied with obstetric, neonatal and postnatal complications. This study aimed to determine the relationship between depression and sleep quality among pregnant women in Tabriz-Iran, 2014.

Materials and Methods: This cross-sectional study was conducted on 565 pregnant women who referred to Tabriz health centers by 2 -stage cluster sampling. The data were collected using socio-demographic questionnaire, Edinburgh Postnatal Depression Scale (EPDS) and Pittsburgh Sleep Quality Index (PSQI). General linear model was used in order to estimate the effect of independent variables (sleep quality and socio-demographic characteristics) on dependent variable (depression).

Results: The mean (SD) of sleep quality score was 3.6 (1.4) from possible score range of 0-21 and the mean (SD) of depression score was 4.7 (3.7) from attainable score of 0-30. A significant correlation was found between depression score and total score of sleep quality and all its sub-domains except delay in sleeping. Also, according to adjusted general linear model, the variables of sleep quality, age, marital relationship, satisfaction of husband job, place of residence and place of receiving prenatal care were predictors of depression.

Conclusion: Considering that the relationship between depression and sleep quality in pregnant women and also maternal and neonatal complications of depression, sleep hygiene education will be necessary in order to improve the quality and quantity of mothers sleep.

Keywords: Depression, Pregnancy, Sleep, Women
\end{abstract}

\section{Introduction}

Many anatomic and physiologic changes occur in women's bodies during pregnancy which make them vulnerable both physically and mentally (1). Depression during pregnancy is the fourth disability factor in the world and it is predicted that it will become the second disability factor by 2020 (2). The relationship between depression history and postpartum depression has been shown which may be followed by adverse consequences such as suicide and child abuse $(3,4)$. Depression rate is remarkable especially in second and third trimester of pregnancy (5). The results of a study showed that pregnancy depression increases the likelihood of cesarean delivery to 2.3 times. The probability of low birth weight is higher in depressed women along with lower mean birth weight and head circumference in infants of depressed mothers (6).

Women sleep quality changes during their reproductive years due to hormonal variations at menstrual cycle, pregnancy and menopause periods (7). Sleep disorder is one of the most common complaints during pregnancy which may be due to physiological, hormonal, cardiovascular and metabolic changes including endocrine changes such as increased levels of progesterone and prolactin, increased size and movements of fetus, distended bladder, diaphragm rise and stomach ache $(8,9)$. Also, fatigue, urinary frequency, husband smoking and education may cause sleep disruption (10). Twenty-five percent of women face with sleep disorder in the first trimester of pregnancy and this rate reaches to $75 \%$ in the third quarter $(11,12)$. It has been found that people with insomnia or severe sleep disorders during pregnancy will have cesarean compared to those who do not have these problems (13).

Sleep disorder also may lead to psychological changes. Evidence has indicated that sleep patterns are the predictive factors for postpartum depression (14). The relationship between poor quality sleep and postpartum depression has been found and significant positive correlation has been reported between sleep quality score in the third trimester of pregnancy and postpartum depression (15). Also, relationship between sleep quality and depression has been reported in pregnant women at 14 weeks of pregnancy age (16). A study results showed that pregnant women sleep time is not more than non-pregnant women despite their increased time in bed; the number

Received 5 January 2016, Accepted 30 August 2016, Available online 21 September 2016

${ }^{1}$ Department of Reproductive Health, Faculty of Nursing \& Midwifery, Tabriz University of Medical Science, Tabriz, Iran. ${ }^{2}$ Department of Reproductive Health, Social Determinants of Health Research Centre, Faculty of Nursing \& Midwifery, Tabriz University of Medical Science, Tabriz, Iran. ${ }^{3}$ Students' Research Committee, Faculty of Nursing \& Midwifery, Tabriz University of Medical Sciences, Tabriz, Iran. ${ }^{4}$ Students' Research Committee, Faculty of Nursing \& Midwifery, Aras International Branch, Tabriz University of Medical Sciences, Tabriz, Iran.

*Corresponding Author: Fatemeh Shiri Sarand, Tel: +989144084624, Email: shirisaranf@gmail.com 
of waking has been increasing from the first trimester and the highest number has been reported in third trimester (12). Yucel et al showed positive weak correlation between mean sleep overall score and depression in their study on 102 pregnant women (17). Skouteris et al in a study on pregnant women showed that sleep quality during early pregnancy may predict a high rate of depression in late pregnancy while no evidence was found on relationship between depression in early pregnancy and sleep quality at late pregnancy (18).

Due to the importance of depression and sleep quality in pregnancy and their possible effects on pregnancy outcomes, the lack of studies in this field in Iran and contrast results of studies as well as socio-cultural differences between different communities, the present study aimed to investigate the relationship between depressions and sleep quality in pregnant women in Tabriz-Iran.

\section{Materials and Methods}

Study Design and Participants

This cross-sectional study was conducted on 565 pregnant women with pregnancy ages equal with 15 weeks or more (the second or third trimester of pregnancy) who visited health centers and bases in Tabriz-Iran in 2014.

The inclusion criteria consisted of having Iranian nationality, being a Muslim, living in Tabriz, willing to participate in the study, having a singleton pregnancy, living with one's husband during the study, and having no employment in night shift. The exclusion criteria included having a multiple pregnancy, pregnancy with fetal abnormalities, history of depression during non-pregnancy period, intense family dispute with husband as asserted by the individual, having infertility history, record of visiting a physician for mental problems, history of taking medicines or hospitalization, medical problems during pregnancy such as thyroid, hypertension and high-risk pregnancy, record of a mental disease - especially depression - in first degree relatives, taking medicines for sleep disorders such as insomnia, oversleeping and frequent waking, facing with problems such as death of relatives, severe accident, serious illness of family members, financial problems, losing one's and husband's jobs and/or the stress caused by changing residence within last six months.

\section{Sampling}

A 2-stage cluster sampling method was used. Sampling was conducted in the health centers and bases of Tabriz city. Among 60 centers and 25 bases in this city, one-third of the health centers and bases (20 centers and 8 bases) were selected randomly through https://www.random. org/. Twenty-one centers were governmental and 8 centers were private. These centers are not referral.

The number of pregnant women selected from reach health center was proportional to the size of the women covered by each center. For sampling, first the number of pregnant women covered by the selected health centers was determined. Then, the names of eligible women were listed, and they were numbered. The final partici- pants to be included in the study were randomly selected based on quota of each center. The selected pregnant women were called and invited for the study. The participants were first assessed in terms of basic information and eligibility criteria. If they were eligible for being included in the study, comprehensive information was provided for them about the aims of study and confidentiality. If they had willingness to participate in the research, informed consent form was filled out by participants and data collection tool was completed via interview with participants.

\section{Data Collection Tool}

Data collection tool included socio-demographic characteristics questionnaire, the Edinburgh Postnatal Depression Scale (EPDS) and Pittsburgh Sleep Quality Index (PSQI).

The EPDS is used to assess depression during pregnancy and postpartum periods. It was developed by Cox et al in 1978. It was revised in 1994 (19). The scale consists of 10 items. Each item has a score from 0 to 3 with the total score of between 0 and 30. A score higher than 12 indicates depression. Montazeri et al has confirmed the validity of the scale (20). This questionnaire was used in different studies on pregnant and delivered women in Tabriz-Iran (21-23). The PSQI measures an individual's attitude toward sleep quality during 4 weeks. It has 7 subscales including subjective sleep quality, sleep latency, sleep duration, habitual sleep efficiency, sleep disturbance, use of sleeping medication and daily daytime dysfunction. The score of each subscale is between 0 and 3 . The sum of the scores of these seven components comprises the total score of the scale ranging from zero to 21 . The lower score shows the better situation of sleep. The score higher than 5 indicates unfavorable quality of sleep. Reliability of the scale was 0.83 and its validity was reported by scale's creators at the appropriate level with the sensitivity of $89.6 \%$ and specificity of $86.5 \%$ in patient participants as compared with the control group (24). The scale was also used in a study on the pregnant women in Tabriz-Iran (25).

\section{Sample Size}

Sample size was estimated 377 individuals with respect to the study of Baghi et al (26) and considering $\mathrm{d}=0.05$ about the mean score of sleep quality $(\mathrm{m}=10.5$, standard deviation $[\mathrm{SD}]=2.5$, and $\alpha=0.05$ ). As it was a cluster sampling, final sample size was calculated 565 individuals with respect to the design effect of 1.5 .

\section{Statically Analysis}

The data was analyzed using SPSS version 21. Descriptive statistic including frequency and percentage, mean, median, percentile 25 to percentile 75 and SD were used for describing socio-demographic characteristics, sleep quality, and depression. Normality of the quantitative data was measured by skewness and kurtosis and they had normal distribution except components of sleep duration, habitual sleep efficiency and use of sleeping medication. Pearson correlation test was used for determining the relationship 
between depression and sleep quality and its components with normal distribution. The Spearman correlation was used for abnormal variables. Any variable was included in the general linear model (GLM) individually in an unadjusted form to determine the relationship between socio-demographic characteristics and the score of depression. Then the variables with $P$ value lower than 0.05 based on unadjusted GLM were entered into the adjusted GLM. The $P$ value lower than 0.05 was considered significant.

\section{Results}

In this study, 612 pregnant women were assessed according to eligibility criteria and 47 women were excluded because they were not eligible. Finally, 565 women participated in the study by filling out the questionnaires.

Mean (SD) age of participants was 28.7 years (5.5) years and body mass index was $25.2(3.2) \mathrm{kg} / \mathrm{m}^{2}$. One-third of participants $(33.5 \%)$ had diploma education and majority of them (98.0\%) were housewives. Almost two-thirds of women $(63.8 \%)$ reported that their monthly income is less than enough amount. Ninety-five percent of women received prenatal care from health centers and about twothirds of respondents (64\%) were satisfied with their husband job. More than three-quarters of women (76.5\%) reported that they were willing to pregnancy. Seventy-eight percent of women and $76 \%$ of their husbands were satisfied with fetal sex (Table 1).
The mean (SD) sleep quality score was 3.6 (1.4) from attainable score of $0-21$ and mean (SD) depression score was 4.7 (3.7) from attainable score of $0-30$. About $6 \%$ of women suffered from sleep disorders. Women had the highest mean score or the worst status in subscale of impaired daily dysfunction and the lowest mean score or the best status in the subscale of hypnotic drugs consumption. According to Pearson test, there was statistically significant correlation between depression score and total score of sleep quality $(P<0.001)$ and sub-domains of subjective sleep quality $(0.016)$, sleep disturbance $(P<0.001)$ and daytime dysfunction $(P<0.001)$; and according to Spearman test, there was statistically significant correlation between depression score and sub-domains of sleep duration $(P<0.001)$, sleep hypnotic drugs $(P<0.001$; Table 2$)$. Also, according to adjusted GLM, the variables of sleep quality, age, marital relationship, satisfaction of husband job, place of residence and place of receiving prenatal care were predictors of depression (Table 3).

\section{Discussion}

In the present study, there was significant correlation between depression score and total score of sleep quality. Also, variables of age, relationship with spouse, consent of the husband's occupation, place of residence and place of receiving prenatal care were predictors of depression. Although, a history of depression is an important risk fac-

Table 1. Socio-Demographic Characteristics of the Participants $(n=565)$

\begin{tabular}{|c|c|c|c|}
\hline Characteristic & No. (\%) ${ }^{a}$ & Characteristic & No. (\%) ${ }^{a}$ \\
\hline Age (y) & & Body mass index $\left(\mathrm{kg} / \mathrm{m}^{2}\right)$ & \\
\hline$<18$ & $6(1.1)$ & $<19.8$ & $11(2.0)$ \\
\hline $18-25$ & $152(27.4)$ & $19.8-25.9$ & $388(70.8)$ \\
\hline $25-30$ & $194(35.0)$ & $26-29$ & $125(22.8)$ \\
\hline$>30$ & $202(36.5)$ & $>29$ & $24(4.4)$ \\
\hline Mean (SD) ${ }^{b}$ & $28.7(5.5)$ & Mean (SD) ${ }^{\mathrm{b}}$ & $25.2(2.3)$ \\
\hline Education level & & Husbands education level & \\
\hline Illiterate & $19(3.4)$ & Illiterate & $10(1.8)$ \\
\hline Elementary & $151(26.7)$ & Elementary & $165(29.2)$ \\
\hline Secondary & $116(20.5)$ & Guidance & $145(25.7)$ \\
\hline High school & $49(8.7)$ & High school & $38(6.7)$ \\
\hline Diploma & 189 (33.5) & Diploma & $152(26.9)$ \\
\hline University & $41(7.3)$ & University & $55(9.7)$ \\
\hline Job & & Sufficiency of income for expenses ${ }^{c}$ & \\
\hline Housewife & 549 (98.0) & Fairly sufficient & $197(36.2)$ \\
\hline Employed & $11(2.0)$ & Insufficient & $347(63.8)$ \\
\hline Residence & & History of abortion & $154(27.3)$ \\
\hline Personal & 207 (36.6) & Place of prenatal care & \\
\hline Rental & $358(63.4)$ & Health center & $538(95.9)$ \\
\hline History of preterm labor & $7(1.2)$ & Private clinic & $5(0.9)$ \\
\hline Marital relationship & & Health center and Private clinic & $18(3.2)$ \\
\hline Very good & $92(16.3)$ & Satisfaction of husband job & \\
\hline Good & $368(65.4)$ & Fairly satisfied & $202(35.8)$ \\
\hline Fairly good & $103(18.3)$ & Completely satisfied & $362(64.2)$ \\
\hline Wanted Pregnancy & $432(76.5)$ & History of depression & $2(0.4)$ \\
\hline Woman interest in fetal sex & $443(78.8)$ & Husband interest in fetal sex & $427(76.3)$ \\
\hline
\end{tabular}

a Valid Percent has been reported in all the variables because of missed data.

${ }^{\mathrm{b}}$ All data indicate number (percent), unless has been specified.

c Two cases reported that the income was completely sufficient. 
Table 2. Status of Depression, Sleep Quality and its Components and Their Relationship $(n=565)$

\begin{tabular}{llcc}
\hline \multirow{2}{*}{ Variable } & Mean (SD) & \multicolumn{2}{c}{$\begin{array}{c}\text { Relationship With } \\
\text { Quality of Life }\end{array}$} \\
\cline { 3 - 4 } & & $\boldsymbol{r}$ & $\boldsymbol{P}$ \\
\hline $\begin{array}{l}\text { Sleep quality total score } \\
\text { Components }\end{array}$ & $3.6(1.4)$ & 0.292 & $<0.001^{\mathrm{b}}$ \\
Subjective sleep quality & $0.8(0.4)$ & 0.102 & $0.016^{\mathrm{b}}$ \\
Sleep latency & $0.8(0.5)$ & 0.020 & $\mathrm{NS}^{\mathrm{b}}$ \\
Sleep duration & $0(0-0)^{\mathrm{a}}$ & 0.164 & $<0.001^{\mathrm{c}}$ \\
Habitual sleep efficiency & $0(0-0)^{\mathrm{a}}$ & 0.238 & $<0.001^{\mathrm{c}}$ \\
Sleep disturbance & $0.8(0.4)$ & 0.291 & $<0.001^{\mathrm{b}}$ \\
Use of sleeping medication & $0(0-0)^{\mathrm{a}}$ & 0.138 & $0.001^{\mathrm{c}}$ \\
Daytime dysfunction & $0.9(0.4)$ & 0.225 & $<0.001^{\mathrm{b}}$ \\
Depression & $4.7(3.7)$ & - & - \\
\hline Abreviations: SD, standard deviation & & & \\
\hline
\end{tabular}

Abbreviations: SD, standard deviation; NS, non-significant.

a These data indicate median (percentile 25-percentile 75).

${ }^{b}$ Pearson test.

cSpearman test. tor for depression during pregnancy but half of women with no previous history of depression at pregnancy are affected (27). Psychosocial approaches including individual and group psychotherapy can be used for treatment of the most of patients with mild to moderate depression and these approaches are rather than drug therapy (28). Therefore, the identification and screening of women with depression in pregnancy can help their treatment and support strategies.

People with insomnia problems experience not only bad sleep during night as compared to those who have a good sleep, but also face significant daily dysfunction. People with poor sleep are anxious and report more fatigue, insomnia and difficulty in focusing compared to those who have a good sleep (29). Reduced stable sleep and increased unstable sleep and awakening at midnight have been observed in depressed patients (30).

In the study of Rad et al, depression of pregnant wom-

Table 3. Relationship Between Socio-Demographic Characteristics and Sleep Quality With Depression in Pregnant Women Based on General Linear Model $(n=565)$

\begin{tabular}{|c|c|c|c|c|}
\hline \multirow{2}{*}{ Variables } & \multicolumn{2}{|l|}{ Unadjusted } & \multicolumn{2}{|l|}{ Adjusted } \\
\hline & $\beta(95 \% \mathrm{Cl})$ & $\boldsymbol{P}$ & $\beta(95 \% \mathrm{Cl})$ & $\boldsymbol{P}$ \\
\hline Total score of sleep quality & 0.78 (0.57 to 0.99$)$ & $<0.001$ & 0.39 (0.20 to 0.57$)$ & $<0.001$ \\
\hline Age (y) (Reference: >30) & - & - & - & - \\
\hline$<18$ & $-0.90(-3.86$ to 2.06$)$ & NS & $-1.90(-4.26$ to 0.46$)$ & NS \\
\hline $18-25$ & $0.52(-0.25$ to 1.28$)$ & NS & $0.63(-0.02$ to 1.28$)$ & NS \\
\hline $25-30$ & $1.04(0.32$ to 1.76$)$ & 0.005 & 1.09 (0.50 to 1.69$)$ & $<0.001$ \\
\hline Education level (Reference: University) & - & - & - & - \\
\hline Illiterate & $0.28(-1.66$ to 2.21$)$ & NS & $-0.53(-2.51$ to 1.44$)$ & NS \\
\hline Elementary & 2.14 (0.91 to 3.37$)$ & 0.001 & $0.42(-0.99$ to 1.83$)$ & NS \\
\hline Secondary & $1.70(0.43$ to 2.97$)$ & 0.009 & 0.59 (-0.78 to 1.97$)$ & NS \\
\hline High school & $2.20(0.72$ to 3.68$)$ & 0.004 & $1.20(-0.28$ to 2.67$)$ & NS \\
\hline Diploma & $0.15(-1.05$ to 1.35$)$ & NS & $-0.15(-1.36$ to 1.06$)$ & NS \\
\hline Husbands education level (Reference: University) & - & - & - & - \\
\hline Illiterate & $0.11(-2.30$ to 2.52$)$ & NS & $-0.54(-2.95$ to 1.88$)$ & NS \\
\hline Elementary & 2.42 (1.32 to 3.51$)$ & $<0.001$ & $1.20(-0.03$ to 2.44$)$ & NS \\
\hline Secondary & 1.16 (0.04 to 2.27$)$ & 0.041 & $0.35(-0.84$ to 1.54$)$ & NS \\
\hline High school & $0.35(-1.13$ to 1.83$)$ & NS & $-0.23(-1.64$ to 1.18$)$ & NS \\
\hline Diploma & $0.61(-0.49$ to 1.72$)$ & NS & $0.58(-0.49$ to 1.66$)$ & NS \\
\hline \multicolumn{5}{|l|}{ Marital relationship (Reference: Fairly good) } \\
\hline Very good & $-3.84(-4.82$ to -2.85$)$ & $<0.001$ & $-1.88(-2.79$ to -0.98$)$ & $<0.001$ \\
\hline Good & $0.09(-2.48$ to -0.95$)$ & $<0.001$ & $-0.84(-1.51$ to -0.16$)$ & 0.015 \\
\hline \multicolumn{5}{|c|}{ Satisfaction of husband job (Reference: Completely satisfied) } \\
\hline Fairly satisfied & 4.02 (3.48 to 4.55$)$ & $<0.001$ & 2.52 (1.95 to 3.09$)$ & $<0.001$ \\
\hline \multicolumn{5}{|l|}{ Residence (Reference: Personal) } \\
\hline Rental & $-0.94(-1.56$ to -0.32$)$ & 0.003 & $-0.55(-1.10$ to -0.00$)$ & 0.049 \\
\hline \multicolumn{5}{|c|}{ Place of prenatal care (Reference: Health center and private clinic) } \\
\hline Health center & $-3.87(-5.56$ to -2.18$)$ & $<0.001$ & $-2.23(-3.66$ to -0.79$)$ & 0.002 \\
\hline Private clinic & $-2.24(-5.82$ to 1.33$)$ & NS & $0.25(-2.92$ to 3.42$)$ & NS \\
\hline \multicolumn{5}{|l|}{ Wanted Pregnancy (Reference: No) } \\
\hline Yes & $-2.28(-2.98$ to -1.59$)$ & $<0.001$ & $-0.69(-1.41$ to 0.03$)$ & NS \\
\hline \multicolumn{5}{|l|}{ Women interest in fetal sex (Reference: No) } \\
\hline Yes & $-2.55(-3.26$ to -1.83$)$ & $<0.001$ & $0.64(-0.74$ to 2.03$)$ & NS \\
\hline \multicolumn{5}{|l|}{ Husband interest in fetal sex (Reference: No) } \\
\hline Yes & $-2.26(-2.95$ to -1.57$)$ & 0.001 & $-0.73(-2.30$ to 0.57$)$ & NS \\
\hline
\end{tabular}

Adjusted $\mathrm{R}^{2}=0.380$

NS refers to non-significant result. 
en with insomnia was nearly twice and there was significant relationship between severity of sleep disorder and depression during pregnancy; also, there was significant relationship between measures of falling asleep, staying asleep and waking up too early and disrupting daily activities and pregnancy depression (31). A study in Iran showed that sleep quality at 28-30 weeks of pregnancy (early third trimester) and 40-38 weeks of pregnancy (late third trimester) is predictor of depression at later stages of pregnancy. Sleep disorder at 28-30 weeks of pregnancy is predictor of increased depression risk at 38-40 weeks of pregnancy and sleep disorders at 38-40 weeks of pregnancy increases the chances of postpartum depression (32). In this study, age was a predictor of depression; there was more depression in 25-30 years old mothers. Bhat et al reported in their study that pregnant women with mean age of 30 years had more depression than 30 years and older women (33).

In this study, people who had a good relationship with their husbands obtained lower depression scores. Karaçam and Ançel reported a significant relationship between unwanted pregnancy and dissatisfied marital status and depression in their study (34).

Satisfaction of husband job was one of depression predictors in pregnant women. The results of a meta-analysis showed that there is strong relationship between job satisfaction and mental problems. People with low job satisfaction tend to experience emotional problems such as low self-esteem, anxiety and depression (35). Also, it is shown that people with high job satisfaction have better mental health compared to those who have low job satisfaction (36). Since people spend most of their time at work and in connection with their jobs during the day, therefore lack of job satisfaction may have negative effects on mental health of people and his relatives and family.

There was a significant relationship between place of residence and depression; participants in rental housing had more depression. Since more people in rental housing have low-income and as found in our study, the majority of participants (64\%) had less than enough income and $63 \%$ of women were living in rental houses, then higher prevalence of depression can be expected in these people. According to the results of this study, there was a significant relationship between care center and depression; people who received care at health centers had less depression. This result may indicate good quality care in Tabriz health centers.

According to the findings of this research and the importance of depression during pregnancy and the relationship between depression and sleep quality in this study, screening, diagnosis and therapeutic interventions for the prevention of depression and improving sleep quality, especially in early pregnancy should be considered as an important issue in women's lives.

Given this is a cross-sectional study, the relationship shown between depression and sleep quality and some socio-demographic and obstetric characteristics do not necessarily indicate a causal relationship. It is suggested to conduct a similar study with longitudinal method. The strong points of this study were sampling method and use of valid and reliable instruments that have been applied in various studies in Iran.

\section{Conclusion}

Given the importance of depression during pregnancy and the relationship between depression and sleep quality in this study, supportive interventions for prevention of depression and improved sleep quality must be considered as important issue in women's lives especially in pregnancy. Because depression causes maternal and neonatal complications, therefore promoting mental and physical health and early identification of depression as well as sleep hygiene education seem necessary in order to improve the quality and quantity of sleep in mothers.

\section{Ethical Issues}

This project was approved by the ethical committee of Tabriz University of Medical Sciences (code of ethics: 5/4/10675).

\section{Conflict of Interests}

The authors declare that there is no conflict of interest.

\section{Financial Support}

Financial support was provided by the Deputy of research of Tabriz University of Medical Science.

\section{Acknowledgments}

Hereby, we acknowledge the Research Department of Tabriz University of Medical Science for financing part of the expenditures and also all the pregnant mothers who participated in the research patiently.

\section{References}

1. Abbaszadeh F, Bagheri A, Mehran NA. Quality of life in pregnant women. J Hayat. 2009;15(1):41-48.

2. Barekatain M, Tavakkoli M, Kheirabadi G, Maracy MR. The relationship between life-time prevalence of bipolar spectrum disorders and incidence of postnatal depression. Iran J Psychiatry Clin Psychol. 2009;15(2):183-192.

3. Abdollahzade RM, Hasanzade AM, Ahmadi S, Taheri M, Hosseini M. Relationship between social support with depression and anxiety during third trimester pregnancy. Iranian J Nurs Res. 2012;7(26):1-10.

4. Hashemi H, Jabbari Z, Haghayegh SA. Survey on effectiveness of cognitive behavioral stress management on the stress, anxiety, and depression of pregnant women. J Health System Res. 2012;8(7):1341-1347.

5. Bennett HA, Einarson A, Taddio A, Koren G, Einarson TR. Prevalence of depression during pregnancy: systematic review. Obstet Gynecol. 2004;103(4):698-709. doi: 10.1097/01.AOG.0000116689.75396.5f.

6. Bahrami N, Bahrami S. Correlation between prenatal depression with delivery type and neonatal anthropometric indicators (Persian). Koomesh. 2013;15(1):39-45.

7. Dzaja A, Arber S, Hislop J, et al. Women's sleep in health and disease. J Psychiatr Res. 2005;39(1):55-76. doi:10.1016/j. jpsychires.2004.05.008. 
8. Lee KA. Sleep and pregnancy/postpartum. J Perinat Neonatal Nurs. 2007;21(2):91. doi:10.1097/01. JPN.0000270623.64584.53.

9. Okun ML, Roberts JM, Marsland AL, Hall M. How disturbed sleep may be a risk factor for adverse pregnancy outcomes. Obstet Gynecol Surv. 2009;64(4):273-280. doi:10.1097/OGX.0b013e318195160e.

10. Jahdi F, Rezaei E, Behboodi MZ, Hagani H. Prevalence of sleep disorders in the pregnant women (Persian). Payesh. 2013;12:629-635.

11. Lee KA, Zaffke ME, McEnany G. Parity and sleep patterns during and after pregnancy. Obstet Gynecol. 2000;95(1):814.

12. Okun ML, Coussons-Read ME. Sleep disruption during pregnancy: how does it influence serum cytokines? J Reprod Immunol. 2007;73(2):158-165. doi:10.1016/j. jri.2006.06.006.

13. Lee KA, Gay CL. Sleep in late pregnancy predicts length of labor and type of delivery. Am J Obstet Gynecol. 2004;191(6):2041-2046. doi:10.1016/j.ajog.2004.05.086.

14. Mirghafourvand M, Charandabi SM, Hakimi S, Khodaie L, Galeshi M. Effect of orange peel essential oil on postpartum sleep quality: A randomized controlled clinical trial. Eur J Integr Med. 2016;8(1):62-66. doi:10.1016/j. eujim.2015.07.044.

15. Alipoor Z, Lamyian M, Hajizadeh E. Sleep quality in late pregnancy and postpartum depression. Iran J Obstet Gynecol Infertil. 2012;14(8):39-47.

16. Jomeen J, Martin CR. Assessment and relationship of sleep quality to depression in early pregnancy [Abstract]. J Reprod Infant Psychol. 2007;25(1):87-99. doi: 0.1080/02646830601117308.

17. Yucel SC, Yucel U, Gulhan I, Ozeren M. Sleep quality and related factors in pregnant women. J Med Sci. 2012;3(7):459463.

18. Skouteris H, Germano C, Wertheim EH, Paxton SJ, Milgrom J. Sleep quality and depression during pregnancy: a prospective study. J Sleep Res. 2008;17(2):217-220. doi: 10.1111/j.1365-2869.2008.00655.x.

19. Cox JL, Holden JM, Sagovsky R. Detection of postnatal depression. Development of the 10-item Edinburgh Postnatal Depression Scale. Br J Psychiatry. 1987;150(6):782786. doi:10.1192/bjp.150.6.782.

20. Montazeri A, Torkan B, Omidvari S. The Edinburgh Postnatal Depression Scale (EPDS): translation and validation study of the Iranian version. BMC Psychiatry. 2007;7:11. doi:10.1186/1471-244X-7-11.

21. Edalati-Fard F, Mirghafourvand M, Mohammad-AlizadehCharandabi S, Farshbaf-Khalili A. Relationship of zinc and magnesium serum levels with postpartum depression in Tabriz-Iran. Glob J Health Sci. 2016;8(11):120. doi:10.5539/ gjhs.v8n11p120.

22. Edalati-Fard F, Mirghafourvand M, Mohammad-AlizadehCharandabi S, Farshbaf-Khalili A, Asghari-Jafarabadi M. The relationship between diet and postpartum depression in postpartum women in Tabriz. Iran J Obstet Gynecol Infertil. 2016;18(182):1-10.

23. Galeshi M, Mirghafourvand M, Abbasnezhad SM, Afsari A.
Relationship between postpartum anxiety and depression and marital satisfaction. J Mazandaran Univ Med Sci. 2016;26(134):351-356.

24. Buysse DJ, Reynolds CF, Monk TH, Berman SR, Kupfer DJ. The Pittsburgh Sleep Quality Index: a new instrument for psychiatric practice and research. Psychiatry Res. 1989;28(2):193-213. doi:10.1016/0165-1781(89)90047-4.

25. Mirghafourvand M, Mohammad ACS, Mansouri A, Najafi $\mathrm{M}$, Khodabande $\mathrm{F}$. The effect of vitamin $\mathrm{d}$ and calcium plus vitamin $\mathrm{d}$ on sleep quality in pregnant women with leg cramps: a controlled randomized clinical trial. J Isfahan Med Sch. 2015;32(320):2444-2453.

26. Baghi V, Ghanei R, Roohi M, Ghoreishi H, Moradi N. The relationship between antenatal depression and sleep apnea. Iran J Obstet Gynecol Infertil 2013;16(52):18-24.

27. Räisänen S, Lehto SM, Nielsen HS, Gissler M, Kramer MR, Heinonen S. Risk factors for and perinatal outcomes of major depression during pregnancy: a populationbased analysis during 2002-2010 in Finland. BMJ Open. 2014;4(11):e004883. doi:10.1136/bmjopen-2014-004883.

28. Yonkers KA, Wisner KL, Stewart DE, Oberlander TF, Dell DL, Stotland N, et al. The management of depression during pregnancy: a report from the American Psychiatric Association and the American College of Obstetricians and Gynecologists. Gen Hosp Psychiatry. 2009;31(5):403-413. doi:10.1016/j.genhosppsych.2009.04.003.

29. Alapin I, Fichten CS, Libman E, Creti L, Bailes S, Wright J. How is good and poor sleep in older adults and college students related to daytime sleepiness, fatigue, and ability to concentrate? J Psychosom Res. 2000;49(5):381-390. doi:10.1016/S0022-3999(00)00194-X.

30. Yang AC, Yang CH, Hong CJ, Tsai SJ, Kuo CH, Peng CK, et al. Sleep state instabilities in major depressive disorder: Detection and quantification with electrocardiogram-based cardiopulmonary coupling analysis. Psychophysiology 2011;48(2):285-291. doi:10.1111/j.1469-8986.2010.01060.x.

31. Rad P, Amir Ali Akbari S, Sadeghniiat K, Alavi Majd $H$. Relationship between sleep disorder and pregnancy depression in primigravidae referring to health-treatment centers of Ahvaz Jundishapur University of Medical Sciences in 2010. J Shahid Sadoughi Univ Med Sci. 2011;19(4):454-62.

32. Asltoghiri M, Ghodsi Z. Study of the relation between sleep disorder and depression at late stage of pregnancy. Procedia Soc Behav Sci. 2011;28:430-4. doi:10.1016/j. sbspro.2011.11.082.

33. Bhat NA, Hassan R, Shafiq M, Sheikh S. Sociodemographic factors: A major predictor of anxiety and depression among pregnant women. Delhi Psychiatry J. 2015;18(1):86-94.

34. Karaçam Z, Ançel G. Depression, anxiety and influencing factors in pregnancy: a study in a Turkish population. Midwifery. 2009;25(4):344-56. doi:10.1016/j. midw.2007.03.006.

35. Faragher EB, Cass M, Cooper CL. The relationship between job satisfaction and health: a meta-analysis. Occup Environ Med. 2005;62(2):105-112. doi:10.1136/oem.2002.006734.

36. Janyam $\mathrm{K}$. The influence of job satisfaction on mental health of factory workers. Internet J Ment Health. 2011;7(1):1-8.

Copyright $\odot 2017$ The Author (s); This is an open-access article distributed under the terms of the Creative Commons Attribution License (http://creativecommons.org/licenses/by/4.0), which permits unrestricted use, distribution, and reproduction in any medium, provided the original work is properly cited. 